\title{
Drug design: 4-thiazolidinones applications. Part 1. Synthetic routes to the drug-like molecules
}

\author{
Roman Lesyk \\ Danylo Halytsky Lviv National Medical University, Ukraine \\ (D) https://orcid.org/0000-0002-3322-0080
}

DOI: https://doi.org/10.20883/medical.406

Keywords: Structure-based drug design, 5-Ene-4-thiazolidinones, Thiopyrano[2,3-d]thiazoles, biological activity, SAR analysis, Michael acceptors
How to Cite: Lesyk R. Drug design: 4-thiazolidinones applications. Part 1. Synthetic routes to the drug-like molecules. JMS [Internet]. 2020 Mar 31;89(1):e406. doi:10.20883/medical.406

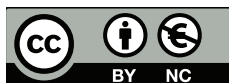

(C) 2020 by the author(s). This is an open access article distributed under the terms and conditions of the Creative Commons Attribution (CC BY-NC) licencse. Published by Poznan University of Medical Sciences

Published: 2020-01-31

\begin{abstract}
4-Thiazolidinones, as examples of privileged scaffolds, have been the focus of medicinal chemistry since $60^{\text {th }}$. Among them, 5-substituted thiazolidinones with a C5 exocyclic bond (5-ene derivatives) are of special interest due to chemical characteristics and pharmacological profiles, possessing anticancer, antimicrobial, and antiviral properties, as well as being high-affinity ligands to a number of biological targets. A new medicinal chemistry trend claims that the aforementioned compounds are frequent hitters or pan assay interference compounds, which are useless because of the possible low selectivity. This is argued by the Michael acceptor property of 5-ene-4-thiazolidinones, which is actively discussed in the literature and requires further investigation. Based on SAR analysis, the main vectors for the design of 5-ene-4-thiazolidinone-based molecules were proposed: complication of $\mathrm{C} 5$ fragment; introduction of the substituents in the N3 position; synthesis of isosteric heterocycles; combination with other pharmacologically attractive fragments; annealing of thiazolidinone core; utilisation of 5-ene-thiazolidinones in synthesis of other compounds. The affinity of 5-ene-4-thiazolidinones toward various targets can be regarded as an advantage in polypharmacological approaches. Michael acceptors are considered as the "new old tool" for new drug creation, especially anticancer agents. One of the possible solutions within privileged substructure-based diversity-oriented synthesis is the fixation of 5-ene-4-thiazolidinone fragment in the fused heterocycles, for example, thiopyrano[2,3-d]thiazoles obtained from 5-ene-thiazolidinones.
\end{abstract}

The 4-thiazolidinone core is well known privileged scaffold in medicinal chemistry and is a powerful tool in the design of new drug-like molecules, especially within rational privileged substructure-based diversity-oriented synthesis [1-6]. Among the diversity of 4-thiazolidinone derivatives, 5-ene-4-thiazolidinone-based com- pounds (Figure 1) are of special interest (most 4-thiazolidinone-based drugs, drug-candidates and lead-compounds belong to the mentioned subtypes). This is outlined in the thesis regarding the crucial role of the C5 substituent's nature in biological activity realisation. The conjugation of the C5-ene fragment to the C4 carbonyl group 


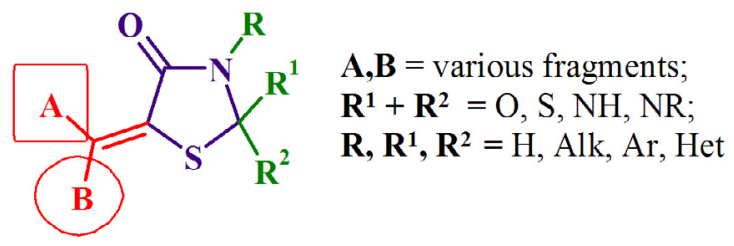

Figure 1. Structure of target 5-ene-4-thiazolidinones

makes such compounds electrophilic and potentially reactive due to the possible Michael addition of the nucleophilic protein residues to the exocyclic double bond compound. Thus, 5-ene-4-thiazolidinones can be treated as Michael acceptors (MA) [7]. The MA in modern medicinal chemistry possessed dualistic features, which characterises 5 -ene-4-thiazolidinones as frequent hitters (promiscuous inhibitors) or pan assay interference compounds (PAINS) that are useless in the drug discovery process because of their possible insufficient selectivity due to the interaction with the biotargets (receptors, enzymes, etc.) [8-11]. However, the low selectivity toward various targets can be regarded as an advantage and baseline for further optimisation, especially in a polypharmacological approach. Many MA are confirmed covalent inhibitors (EGFR-, PI3K-, BTK-, MEK-inhibitors etc.) with anticancer properties, with the presence of the MA-moiety increasing the selectivity of known ligands. MA are inductors of phase 2 enzymes and inducible phase 2 proteins that can be treated as new approach for cancer treatment. Such MA are effective activators of Nrf2 through the Keap1 modification that opens new perspectives in the treatment of inflammation, cancer and chemoprevention. Moreover, MAproperties, calculated or predicted in silico, are often not confirmed experimentally (under conditions close to physiological). Currently, the MA are assigned as "old new tool" for anticancer agent design [12,13].

In an attempt to solve this confusion ("negative and positive" profiles of 5 -ene-4-thiazolidinones) in the spirit of drug design and discovery, we propose two approaches, "biological" and "chemical". The biological approach is based on the hypothesis regarding the crucial role of the presence/nature of the C-5 substituent of the 4-thiazolidinone core for biological activity realisation and involves the design of new active molecules and the development of directions of 4-thiazolidinone core modification to increase the selectivity and activity level of compounds. The advantage of this approach is that most hit- and lead-compounds belong to the 5-ene-4 -thiazolidinones [12-14]. The chemical approach is based on our hypothesis that active 5-ene-4thiazolidinone fixation in fused thiopyrano[2,3-d] thiazoles allows conservation of the activity vector, therefore opens new possibilities of molecule optimisation. Thus, fused thiazolidinone-based heterocycles could be of special interest as cyclic mimetics of 5-ene-4-thiazolidinone precursors without MA properties [15]. For this reason, rows of different thiopyrano[2,3-d][1,3]thiazoles were designed and synthesised and their anticancer potential was confirmed.

The synthetic strategy is grounded on thiazolidinone-based design, involving a combinatorial approach, diversity-oriented synthesis as well as privileged sub-structure-based diversity-oriented synthesis (bioisostere replacement, natural compounds modifications etc.). Additionally, molecular hybridisation as one of the most employed approaches in new anticancer drug design, allows the design of hybrid molecules where the combination of several privileged scaffolds has been regarded as a benefit.

\section{The "biological" method of drug-like molecule design}

SAR analysis outlined the main directions for 4-thiazolidinone optimisation: complication of $\mathrm{C5}$ fragment; modification of $\mathrm{N} 3$ and $\mathrm{C} 2$ positions; the isosteric replacement; creation of hybrid molecules via combination of thiazolidinone core with other "pharmacologically attractive" fragments (pyrazoline, pyridine, indole, benzothiazole, etc.). Thus, the reaction of (benzothiazol-2-yl)hydrazine with trithiocarbonyl diglycolic acid yielded starting 3-(benzothiazol-2-ylamino)-2-thioxo-4thiazolidinone 1, which was subsequently utilised in a Knoevenagel condensation to obtain a series of 5 -arylidene derivatives 2 (Scheme 1, Figure 2) $[16,17]$. The acetylation of exocyclic nitrogen was observed (3) following acetic anhydride addition to reactive mixture. A similar pattern with the formation of $\mathrm{N}$-acetylsubstituted 5-ethoxymethylene-2-thioxo-4-thiazolidinone 4 was observed in the condensation of 1 with triethyl orthoformate in 
<smiles></smiles>

$Z$-Hydrazone form

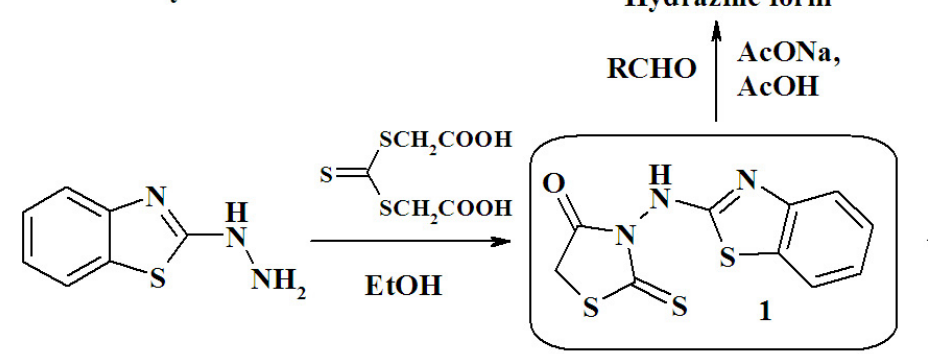<smiles>CCO/C=C1\SC(=S)N(N(C(C)=O)c2nc3c(C(=O)O)cccc3s2)C1=O</smiles><smiles></smiles>

$E$-Hydrazone form<smiles>[R]C=C1SC(=S)N(N(C(C)=O)c2nc3ccccc3s2)C1=O</smiles>

Figure 2. Scheme 1

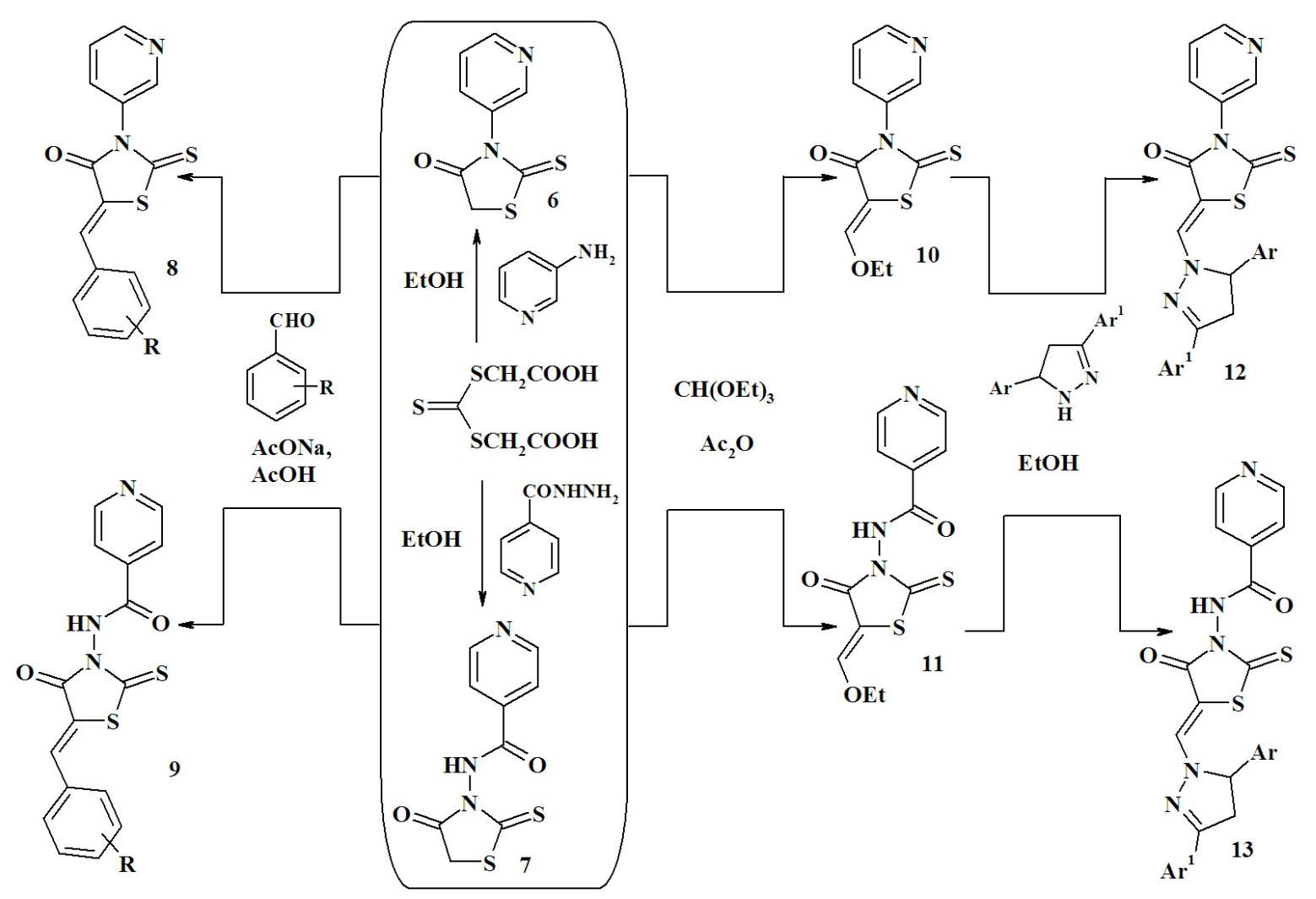

Figure 3. Scheme 2 
acetic anhydride. The 5-ethoxymethylene derivative 4 was converted into appropriate enamines 5 .

Following the reaction of 3-aminopyridine or isoniazid with trithiocarbonyl diglycolic acid in an ethanol medium, 3-pyridine substituted rhodanines 6,7 were obtained. Derivatives 6 and 7 are methylene active heterocycles, which yield a series of 5-arylidene derivatives 8, 9 in the Knovenagel reaction. Moreover, the 5-ethoxymethylene derivatives 10 and 11 were synthesised by the condensation of 6 and 7 with triethyl orthoformate in acetic anhydride. As the amine component in the aminolysis reaction, we tested some 3,5-diarylpyrazolines, which allowed the synthesis of new pyrazoline-thiazolidinone conjugates 12 and 13 (Scheme 2, Figure 3) [18-21].

Condensation of 2-(4-oxo-2-thioxothiazolidin3-yl)-3-phenylpropionic acid 14 with triethyl orthoformate yielded 5-ethoxymethylene derivative 15 . Interestingly, the simultaneous esterification of the carboxylic group resulted in the ester formation. Compound 15 was converted into appropriate enamines 16-18 (Scheme 3, Figure 4) [22].
It is known that the reaction of 2-chloroacetamides with thiocyanates does not stop at the nucleophilic substitution stage, but passes spontaneous heterocyclisation with the formation of a 4-thiazolidinone ring and the Dimroth rearrangement with the migration of the substituents in positions 2 and 3 . Using this method, various 1,3,4-thia(oxa)diazol-substituted 2-imino-4-thiazolidinones 19 were synthesised (Scheme 4, Figure 5) $[18,23]$. Compounds 19 were utilised to obtain 5-ene derivatives 20, 21.

Spiro-substituted 4-thiazolidinone-isatins 22 were obtained in a three-component onepot reaction of isatin, corresponding to aromatic amine and thioglycolic acid (Scheme 5, Figure 6). The synthesis of 5-arylidene-4-thiazolidinones 23 is described in the Knoevenagel reaction under different conditions. Although commonly used conditions (sodium acetate as catalyst in acetic acid) are not effective in the case of 2-substituted-4-thiazolidinone because of the low reactivity of the methylene group in comparison with rhodanine or 2,4-thiazolidinedione derivatives, the reac-

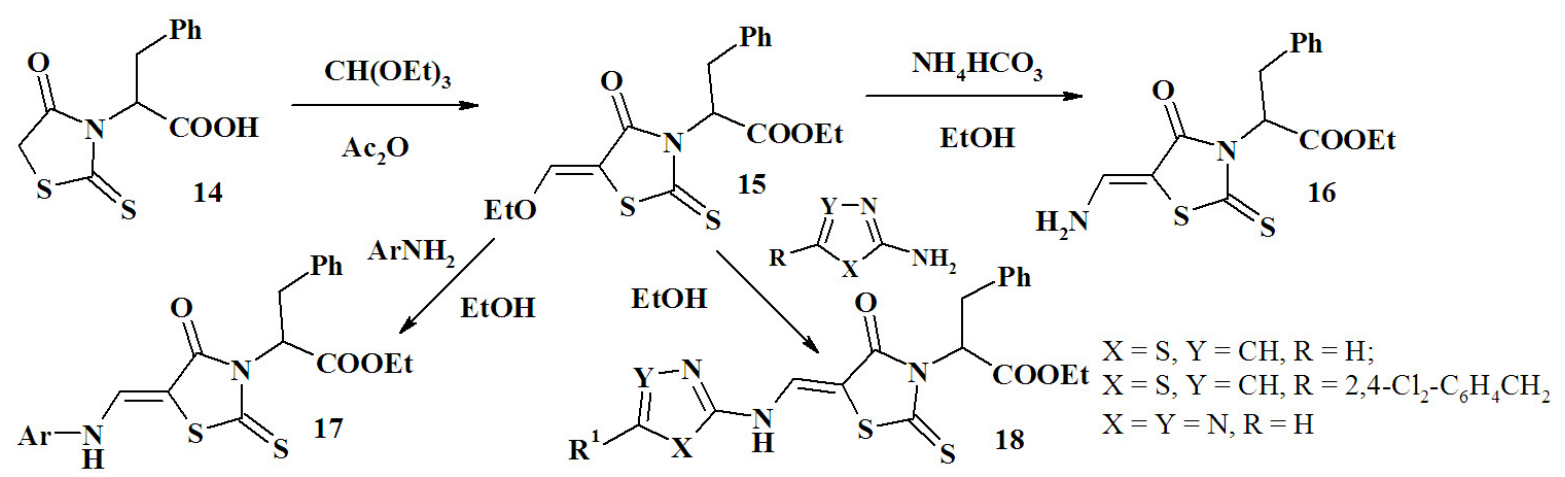

Figure 4. Scheme 3
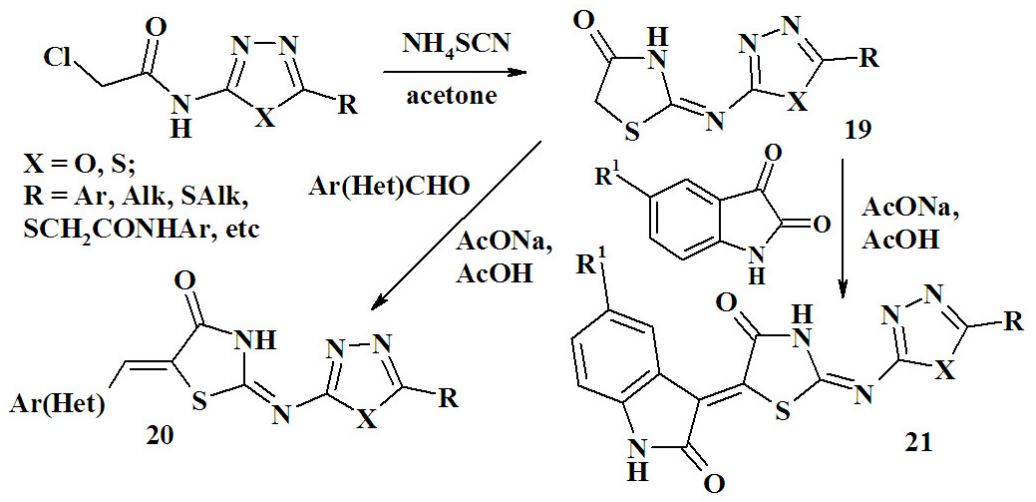

Figure 5. Scheme 4 
tion was performed in isopropanol with the presence of potassium tert-butylate as a catalyst [24].

The interaction of 3,5-diaryl-4,5-dihydro- $1 \mathrm{H}$ pyrazoles with 4-thioxo-2-thiazolidinones (isorhodanines) yielded 4-pyrazoline-substituted-1,3-thiazole-2-one 24, which were utilised for the synthesis of 5-arylidene derivatives 25 (Scheme 6, Figure 7) [25].
Detailed biological activity evaluation of pyrazoline-thiazolidinone conjugates 28-32 (Scheme 7, Figure 8) synthesised via the [2+3]-cyclocondensation of 4,5-dihydropyrazole-1-carbothioamides 26 as S,N-binucleophilesand dielectrophilic synthon [C2]2+ allowed the identification of compounds with antimicrobial, antiviral, antiinflammatory and antitumor activities. For the<smiles>[R]c1ccc(N2C(=O)/C(=C/[Al-]C(C)C(C)(C)O)SC23C(=O)Nc2ccccc23)cc1</smiles>

Figure 6. Scheme 5<smiles>[X]c1ccccc1C1CC(c2ccccc2)=NN1</smiles><smiles>[R]c1cccc(C2CC(c3ccccc3)=NN2C2=NC(=O)SC2)c1</smiles>

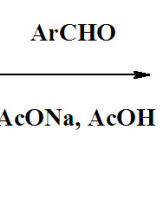<smiles>[R]c1ccccc1C1CC(c2ccccc2)=NN1C1=NC(=O)S/C1=C\[Al]</smiles>

Figure 7. Scheme 6<smiles>[Y4]COC(=O)CSC1=NC(=O)CS1</smiles><smiles>CC(C=O)C(=O)OCC(=O)O</smiles><smiles>[Y]c1ccccc1C1CC(c2ccccc2)=NN1C1=NC(=O)/C(=C/[12F])S1</smiles>
29<smiles>[R]c1ccc(C(=O)CC2SC(N3N=C(c4ccccc4)CC3c3ccccc3)=NC2=O)cc1C(=O)/C=C\C(=O)O</smiles>

AcONa, AcOH

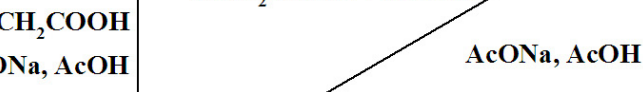

Figure 8. Scheme 7 
synthesis of target derivatives, chloroaceitc acid, maleic anhydride, maleimides and $\beta$-aroylacrylic acids were used as equivalents of dielectrophilic synthon [C2]2+. The tree-component one-pot reaction including $[2+3]$-cyclocondensation of 4,5-dihydropyrazole-1-carbotioamides 26 with chloroacetic acid and the further Knoevenagel reaction with aromatic aldehydes or isatin derivatives is an effective approach for the design of new anticancer agents from pyrazoline-thiazolidinones 29, 30. Alternatively, 2-(5-aryl-3-phenyl4,5-dihydro-1H-pyrazol-1-yl)-1,3-thiazol-4(5H)ones 28 were obtained following the reaction of 2-carbethoxymethylthio-2-thiazoline-4-one 27 with appropriate 5-aryl-3-phenyl-2-pyrazolines in ethanol [25-27].

Continuing systematic synthetic studies of heterylsubstituted 4-thiazolidinone, a series of thiosemicarbazones 34 was obtained based on 6-arylimidazo[2,1-b]thiadiazole-5-carbalde-

hydes 33 . The synthesis of the target thiazolidinone/thiazole-indole/imidazothiadiazole hybrids 35-38 was performed via the reaction of [2+3]cyclocondensation. a-Halogenocarboxylic acids, ethyl-2-chloroacetoacetate, 2-bromoacetophenone, and 2-bromobutyrolactone were used as [C2]2+ reagents. When utilising 2-bromobutyrolactone, compounds with free or acetylated $\mathrm{OH}$ group were obtained depending on the reaction medium (Scheme 8, Figure 9). The synthesis of these compounds was confirmed by our preliminary data on the high antitrypanosomal activity of 2-hydrazono-4-thiazolidinones with arylindole moiety in position 2, which are bioisosteric to 6-arylimidazo[2,1-b]thiadiazole [28].

Next, new oleanolic acid (OA) derivatives with 4-thiazolidinone-carboxylic acids fragments were designed as new potential anticancer agents. The design of the target compounds is outlined on Scheme 10 (Figure 11) and consists of the modification of OA A-ring-linking group by heterocyclic acids, with the use of oxime group as a linker. Starting oximes 43 were synthesised by reacting hydroxylamine hydrochloride with 3-oxooleanolic acid 39, its methyl ester 40, morpholide 41 or 12-bromolactone 42 in ethanol in the presence of anhydrous sodium acetate. The mentioned 3-oxooleananes 39-42 were obtained from $O A$ extracted from Viscum album, L. For the synthesis of target 3-0-acyloleanolic acid derivatives 44 , the oximes 43 were acylated by 4 -thiazolidinone-based heterocyclic acids in the presence of $\mathrm{N}, \mathrm{N}^{\prime}$-dicyclohexylcarbodiimide (DCC) in dioxane or THF at room temperature (Scheme 9, Figure 10). As a result, we designed and synthesised new semi-synthetic compounds with possible satisfactory ADME-tox parameters. Moreover, the oleanane fragment of these derivatives could be considered as an element of drug-delivery systems [29].

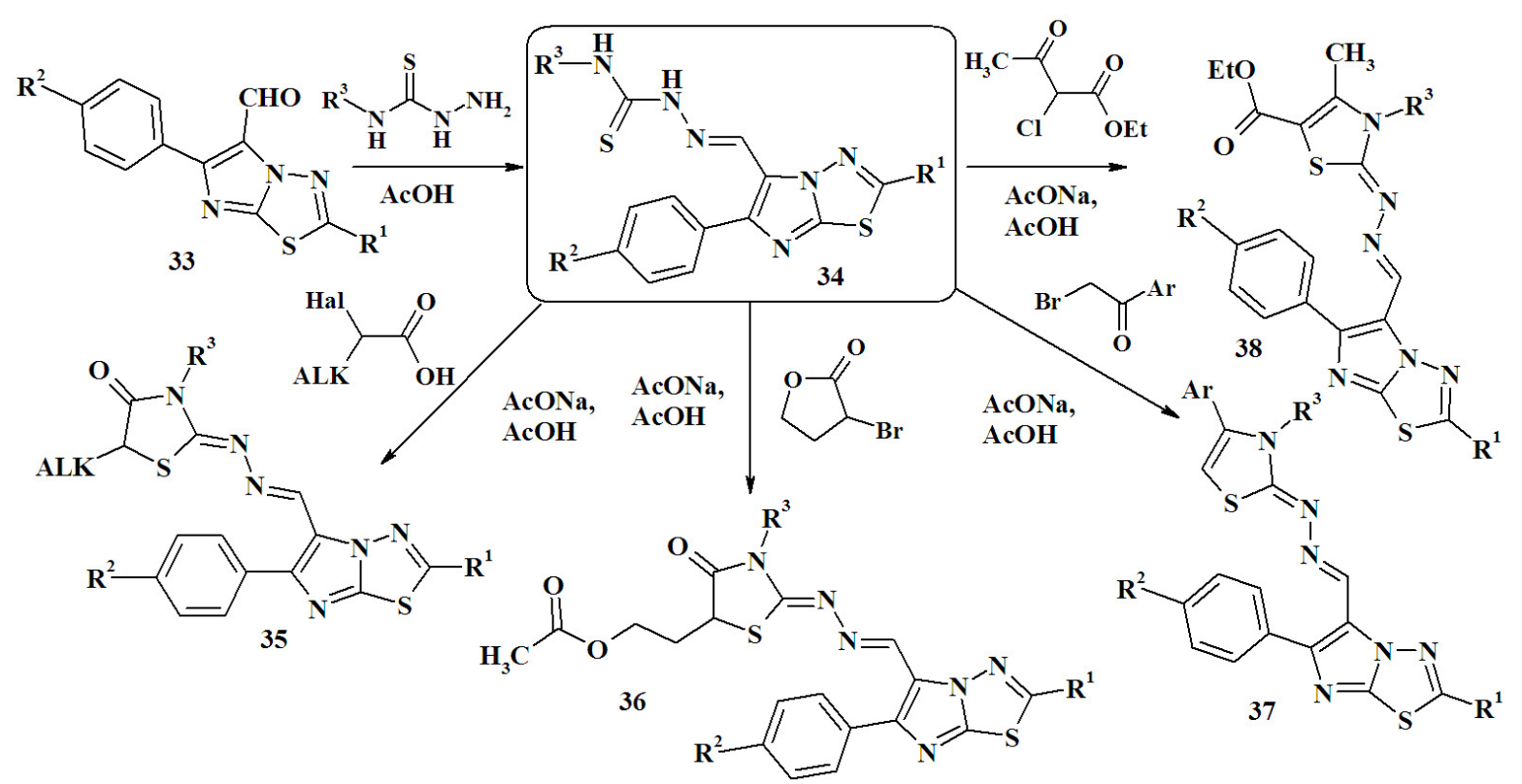

Figure 9. Scheme 8 

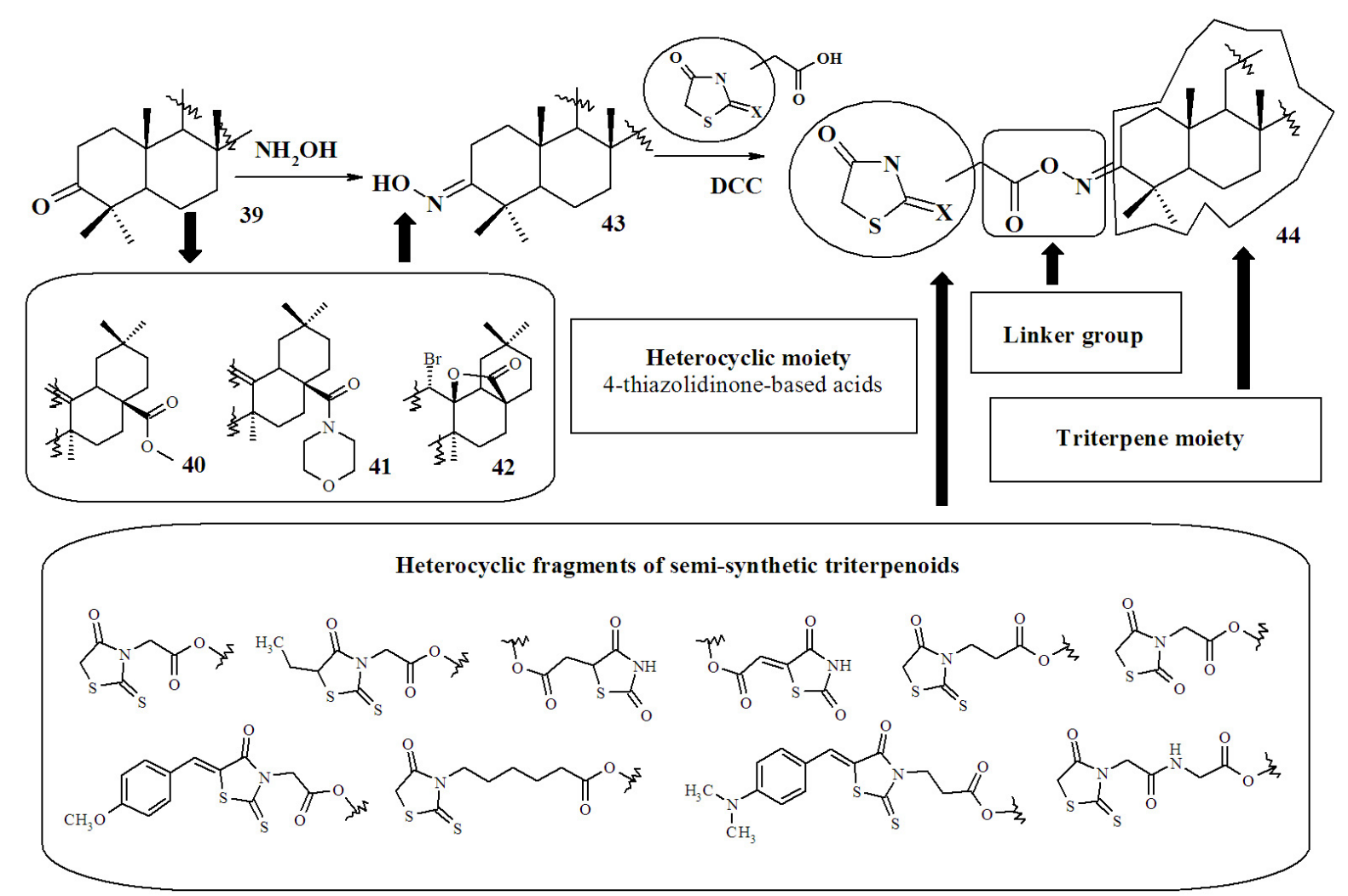

Figure 10. Scheme 9

\section{"Chemical" approach for the design of drug-like molecules}

The "Chemical" approach is based on the hypothesis that thiopyranothiazole scaffold can be treated as "fixed" 4-thiazolidinone biophore in a "rigid" fused heterocyclic system, thereby preserving the biological activity of synthetic precursors, namely 5-ene-4-thiazolidinones. Thiopyranothiazoles can be considered as biomimetics of pharmacologically active 5-ene-4thiazolidinones without MA properties (Scheme 10, Figure 11). The combination of thiazole and thiopyran cycles in a condensed heterosystem is a precondition for the creation of "centres conservative" of the ligand-target binding complex and promotes potential selectivity to biotargets.
Considering the aforementioned arguments, the directed search for new drugs among fused thiazole-based derivatives is justified and a promising direction in modern medicinal chemistry [15].

The most efficient approach to thiopyrano[2,3-d]thiazoles design is the use of the hetero-Diels-Alder reaction, and 5-ene-4-thioxo2-thiazolidinones (5-ene-isorhodanines) with 5-ene-2,4-thiazolidinedithiones (5-ene-thiorhodanines) as heterodienes (Scheme 11, Figure 12). These reagents contain in their structure a, $\beta$-unsaturated thiocarbonyl fragment similar to the 1-thio-1,3-butadiene which leads to their high reactivity in the $[4+2]$-cycloadditions. The important condition is the presence of a strong dienophile with electron acceptor properties to decrease the energy difference between diene's<smiles>[Y]C([Y8])C1SC(=[X])N([Y])C1=O</smiles><smiles>[R]NC=C</smiles><smiles>[Y]N1C(=O)/C(=C/[In])SC1=[V]</smiles><smiles>[R]NC(C)(C)C(C)(C)C</smiles>

Figure 11. Scheme 10 


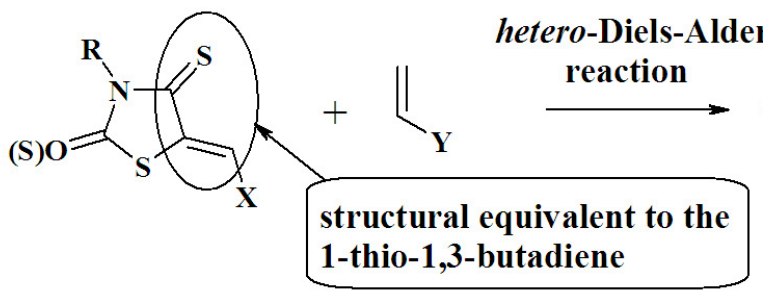

Figure 12. Scheme 11

"HOMO" and "LUMO" or "HOMO" of the dienophile. For these reasons, reactions are highly regioselective [30].

In the pioneering works of our department, the dienophile component was represented by maleic acid and its derivatives (maleic anhydride, maleinimides) and acrylic acid and its derivatives (methyl acrylate, ethyl acrylate, acrylonitrile) [31-33]. Currently, we have significantly expanded the list of dienophiles. Thus, the use of cynnamic acids and their amides [34], aroylacrylic

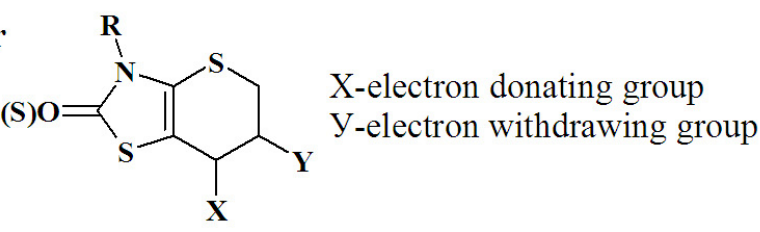

thiopyrano[2,3-d] thiazoles
[35] and arylidenepyruvic acids [36] as well as dimethyl acetylenedicarboxylate [37], propiolic acid and its ethyl ester [38], acroleine [39], 2-norbornene $[40,41]$ and 5-norbornene-2,3-dicarboxylic acid imides [42] as dienophiles yielded new thiopyrano[2,3-d]thiazoles 45-52 (Scheme 12, Figure 13).

We established that the reaction of 5-arylideneisorhodanines with $2(5 \mathrm{H})$ furanone yielded mixtures of endo/exo adducts 53,54 (Scheme 13, Figure 14). Considering the moderate diastereo-

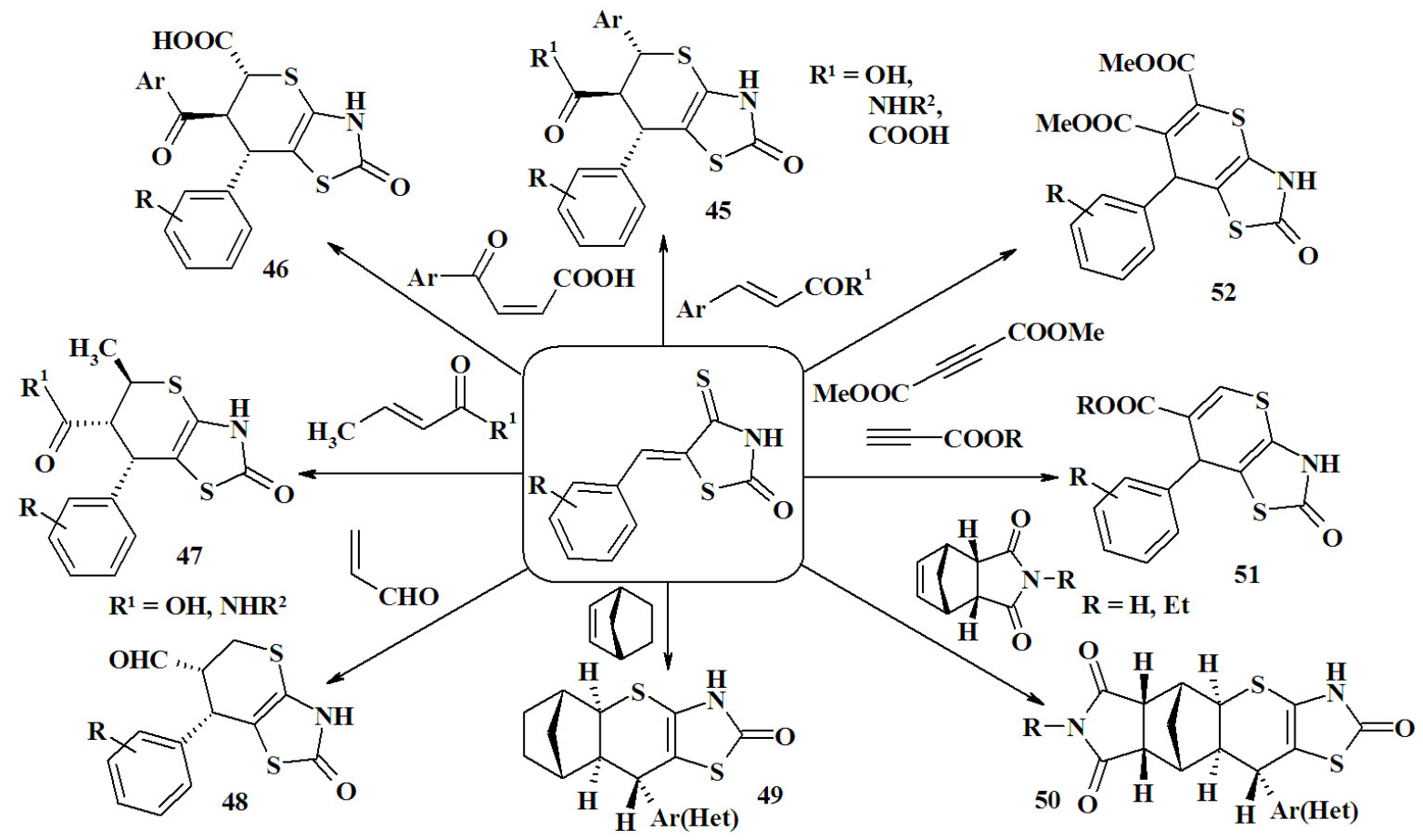

Figure 13. Scheme 12<smiles>CC1C=CC(=O)O1</smiles><smiles>[14CH3][C@H]1c2sc(=O)[nH]c2S[C@@H]2COC(=O)[C@H]21</smiles><smiles>[Y19]C1c2sc(=O)[nH]c2S[C@H]2COC(=O)[C@H]12</smiles>

Mixture of $r e l-4 \mathrm{a} R, 7 \mathrm{a} R, 8 S$ and rel-4a $R, 7 \mathrm{a} R, 8 R$-stereoisomers (endo/exo)

Figure 14. Scheme 13 
selectivity, the reaction can occur through endo or exo transition states. Thus, the endo transition state leads to anti configuration, while the exo geometry results in syn configuration of the $8-\mathrm{H}$ respectively [43].

The reaction of 5-arylideneisorhodanines with trans-aconitic acid proceeds as a regioand diastereoselective [4+2]-cycloaddition with spontaneous decarboxylation of the adduct 55 to furnish rel-(6R,7R)-diastereomers 56 . The same products were synthesised using itaconic acid as dienophile. Interestingly, the one-pot three-component reaction of 5-arylideneisorhodanines, trans-aconitic acid and anilines diastereoselectively yielded rel-(5'R,6'R,7'R)-spiro[pyrrolidin3,6'-thiopyrano[2,3-d]thiazol]-2,2',5-triones 57 without decarboxylation of adducts. The thiopyrano[2,3-d]thiazoles 90 were synthesised using (2,5-dioxo-1-arylpyrrolidin-3-ylidene)-acetic acids as dienophiles. It should be noted that unlike free trans-aconitic acid or its imides, the corresponding trimethyl ester (trimethyl 1-propene-1,2,3-tricarboxylate) reacted with opposite regioselectivity resulting in [4+2]-cycloadducts (58) (Scheme 14, Figure 15) [44].

In the case of utilisation of 1,4-naphthoquinone as a dienophile, intermediates of the [4+2]-cycloaddition reaction undergo spontaneous oxidation with the formation of tetracyclic thiopyrano[2,3-d]thiazoles 59 (Scheme 15, Figure 16) [45].

It is known that [4+2]-cycloaddition of 5-ethoxymethylidene-4-thiazolidinethiones with dienophiles in boiling acetic acid passes with

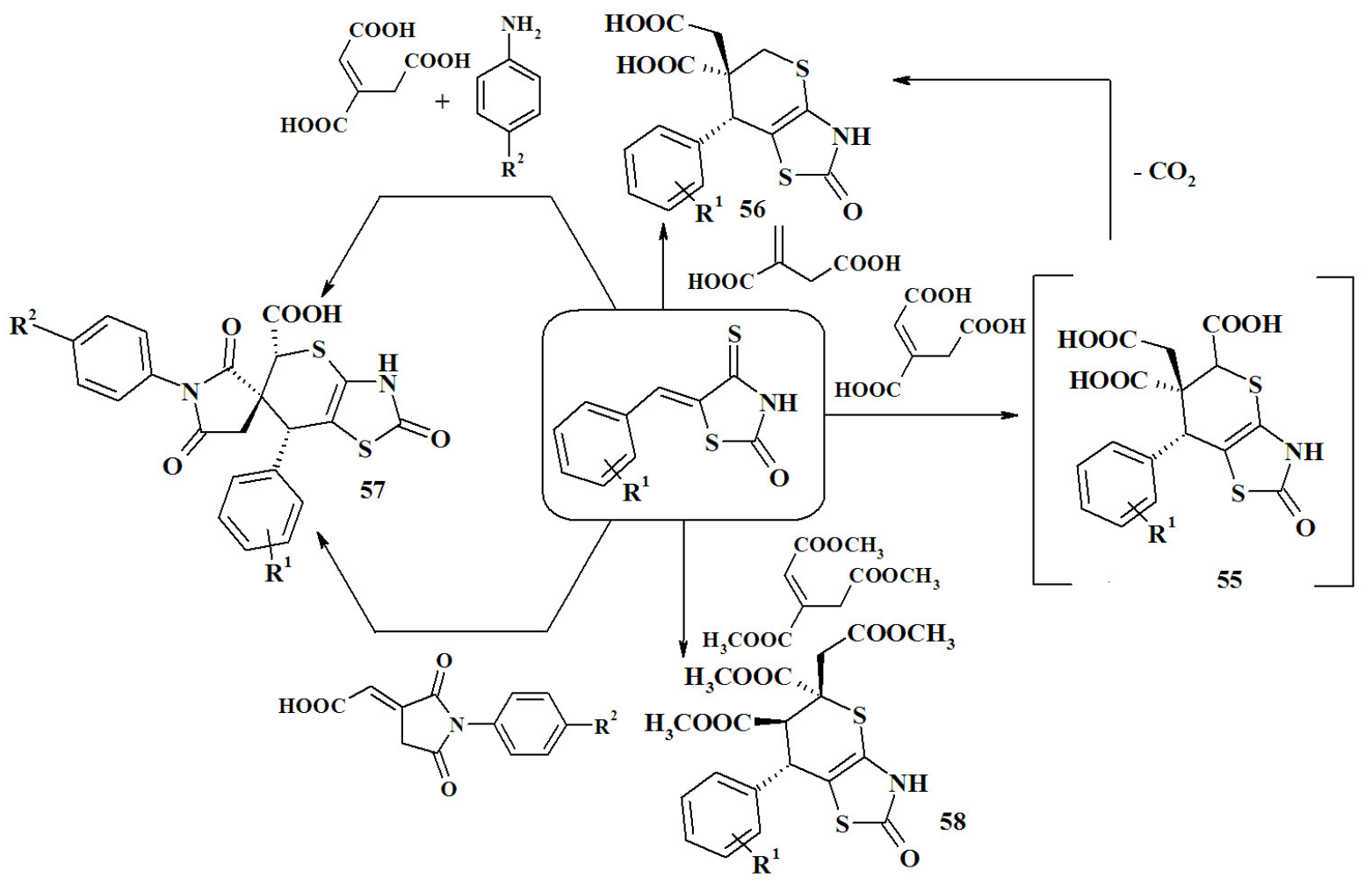

Figure 15. Scheme 14

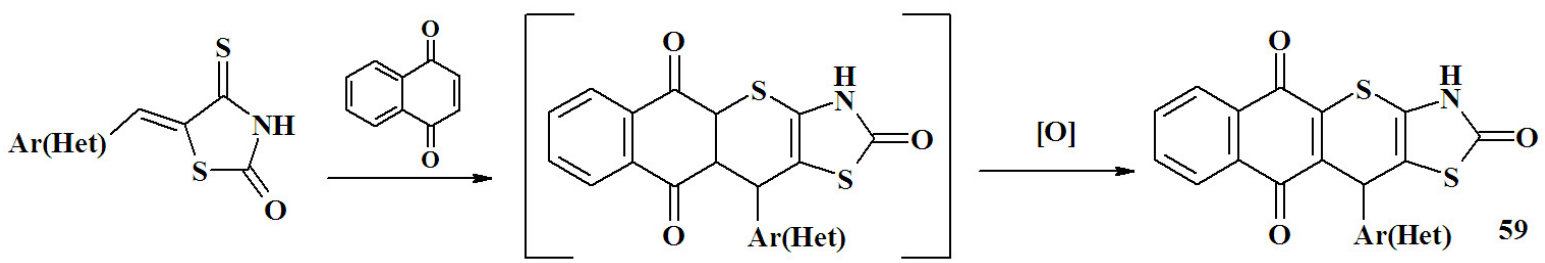

Figure 16. Scheme 15 
spontaneous ethanol elimination and the formation of 3,5-dihydro-2H-thiopyrano[2,3-d]thiazoles. Analogously, we observed in the [4+2]cycloaddition with acrolein, crotonic aldehyde, 2-norbornene and 5-norbornene-2,3-dicarboxylic acid imides (60-62). When the interaction of 5-ethoxymethylene-4-thioxo-2-thiazolidinones with propiolic acid is accompanied by not only the ethanol elimination, but the rearrangement of double bonds with the formation of 2-oxo-2 $\mathrm{H}-$ thiopyrano[2,3-d]thiazole-6-carboxylic acid 63, compound 63 is also formed when using acetylene dicarboxylic acid, which may be explained by additional adduct decarboxylation. [4+2]-Adducts of aroylacrylic acids also undergo elimination of ethanol and decarboxylation with regioselective formation of 64. Interaction with the 1,4-naphthoquinone was accompanied by spontaneous dehydrogenation and ethanol elimination yielding derivative 98 (Scheme 16, Figure 17) [46].

One of the relatively new areas in thiopyrano[2,3-d]thiazole chemistry is the usage of 5-(cyclo)alkylideneisorhodanines as key reagents (Scheme 17, Figure 18). Thus, the strating heterodienes 66 were obtained in the reaction of isorhodanine with acetone, cyclopentanone or cyclohexanone at room temperature and in the presence of triethylamine as a catalyst. Interestingly, performing the reaction in ethanol at the solvent boiling point leads to the formation of tricyclic heterosystems 67 . When thiorhodanine is used, only fused derivatives 68 are formed regardless of the reaction conditions. [4+2]Cycloaddition of 66 with maleinamides, 2-norbornene and (3,5-dioxo-4-azatricyclo[5.2.1.02,6] decen-8-yl-4)-acetic acid yielded derivatives 69-71 [47].

As a phase of study of the hetero-Diels-Alder reaction, we suggested new tandem and domino processes for the synthesis of polycondensed thiopyranothiazole-based compounds. These reactions allow the synthesis of structurally complex molecules with high selectivity, while the usage of solvents, reagents, adsorbents and energy is significantly reduced compared to traditional multistage synthetic approaches.

The presence of active groups in the o-position of 5-arylidene-4-thiazolidinethiones is an important feature contributing to the passing of tandem processes based on the hetero-DielsAlder reaction. Among the tandem reactions, we distinguished two types of processes: acylationand hemiacetal-based reactions (Scheme 18, Figure 19). The first approach requires the use of

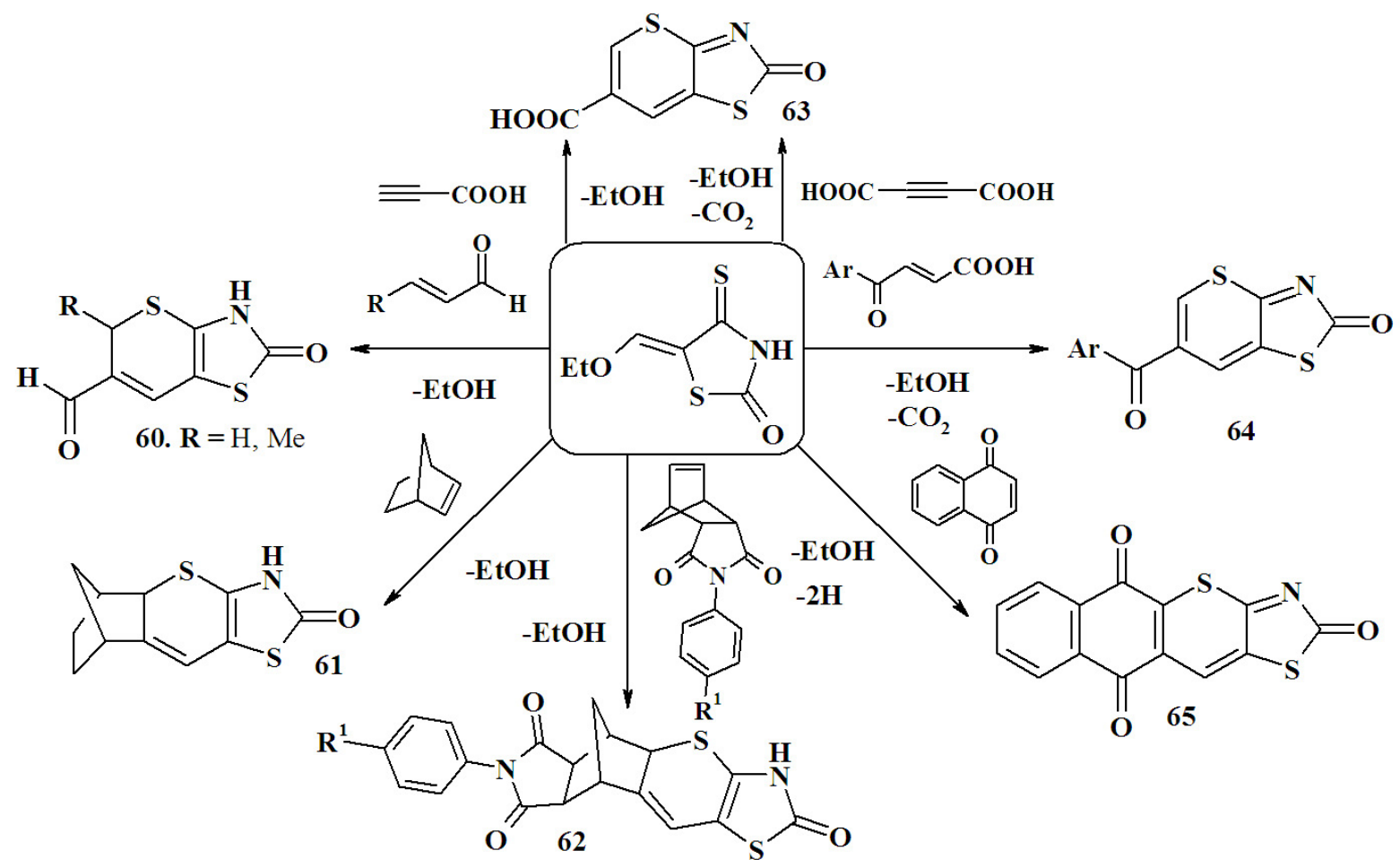

Figure 17. Scheme 16 


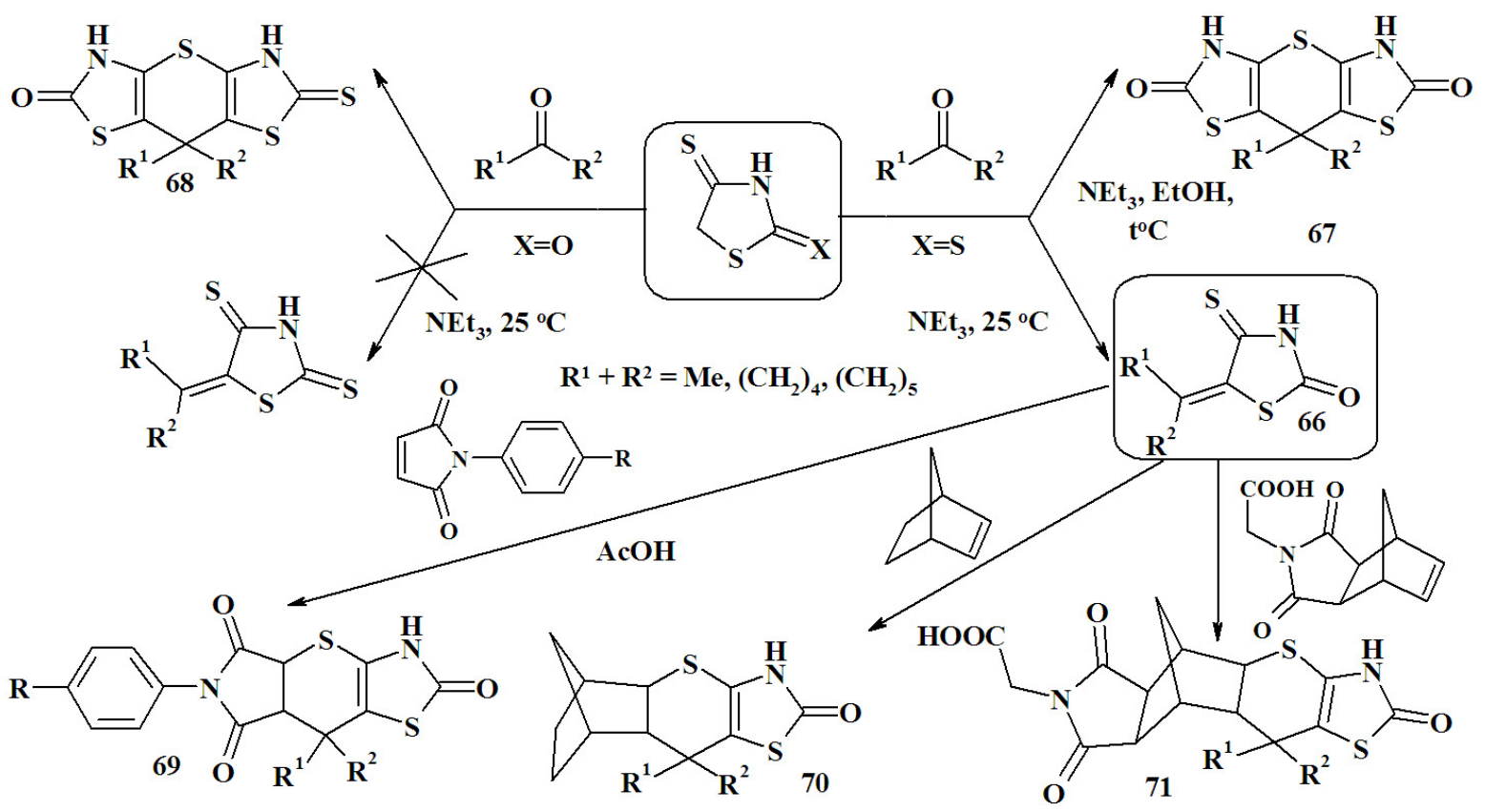

Figure 18. Scheme 17
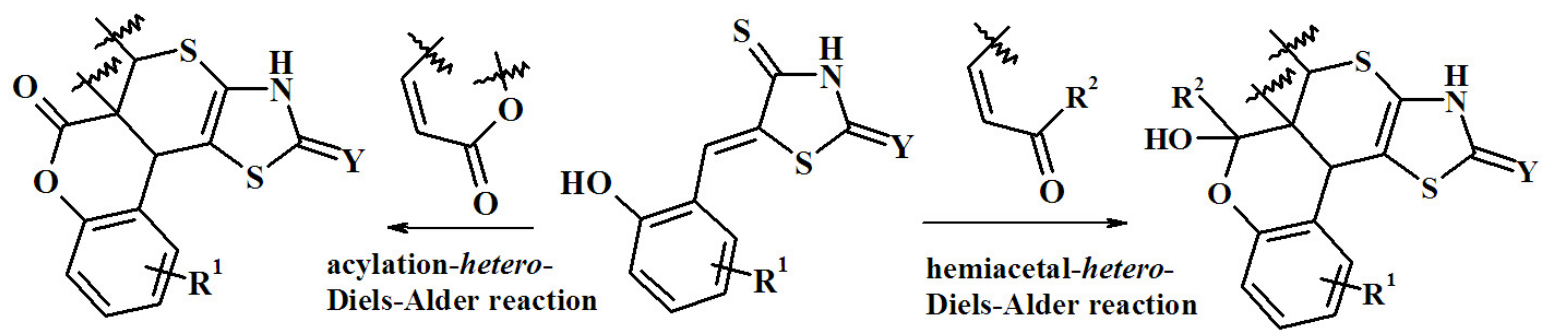

Figure 19. Scheme 18

derivatives of $\alpha, \beta$-unsaturated carboxylic acids as dienophiles, and $a, \beta$-unsaturated oxo compounds (aldehydes and ketones) in the second.

Thus, when studying hetero-Diels-Alder-acylation tandem reactions of 5-(2-hydroxyphenylmethylidene)isorhodanines 72 with unsaturated carboxylic acids and their derivatives more precisely, a number of stereochemical peculiarities of these processes were established (Scheme 19, Figure 20). For example, in the reaction of crotonic acid, its amides or anhydride, a mixture of rel$5 \mathrm{R}, 5 \mathrm{aR}, 11 \mathrm{bS}$ and rel-5S,5aR,11bS diastereomers (73) was formed. The reaction of heterodiene 72 with maleic and fumaric acids and their derivatives (maleic anhydride, esters) passed diastereoselectively. Moreover, independently of the stereoisomerism of the dienophile, a racemic mixture of rel-(5R,5aR,11bS) derivatives 74 was formed. Itaconic acid and its anhydride as well as transaconitic acid reacted in a similar manner forming derivative 75 . In the case of trans-aconitic acid, the reaction proceeded with spontaneous decarboxylation at position 5 of thiopyrano[2,3-d]thiazole core. rel-(5S,5aR,11bS) derivative 76 was the product of tandem hetero-Diels-Alder-acylation reaction of 72 and cynnamic acids. Compound 75 proved to be an effective reagent for the next chemical transformations. The reaction of 75 with primary amines in acetic acid passed through the amidation stage, followed by spontaneous recycling in spiroimides 77 . The thiopyrano[2,3-d]thiazoles 77 were also obtained by the alternative method from itaconic acid imides $[38,44,48,49]$.

It is important to note that in the reaction of propiolic acid, a classic hetero-Diels-Alder reaction takes place to form 78. The presence of a double bond at positions 5-6 causes planar structure of the bicyclic fragment and creates the spatial obstacles for acylation of the phenolic group. Dehydrogenation of the basic hetero- 


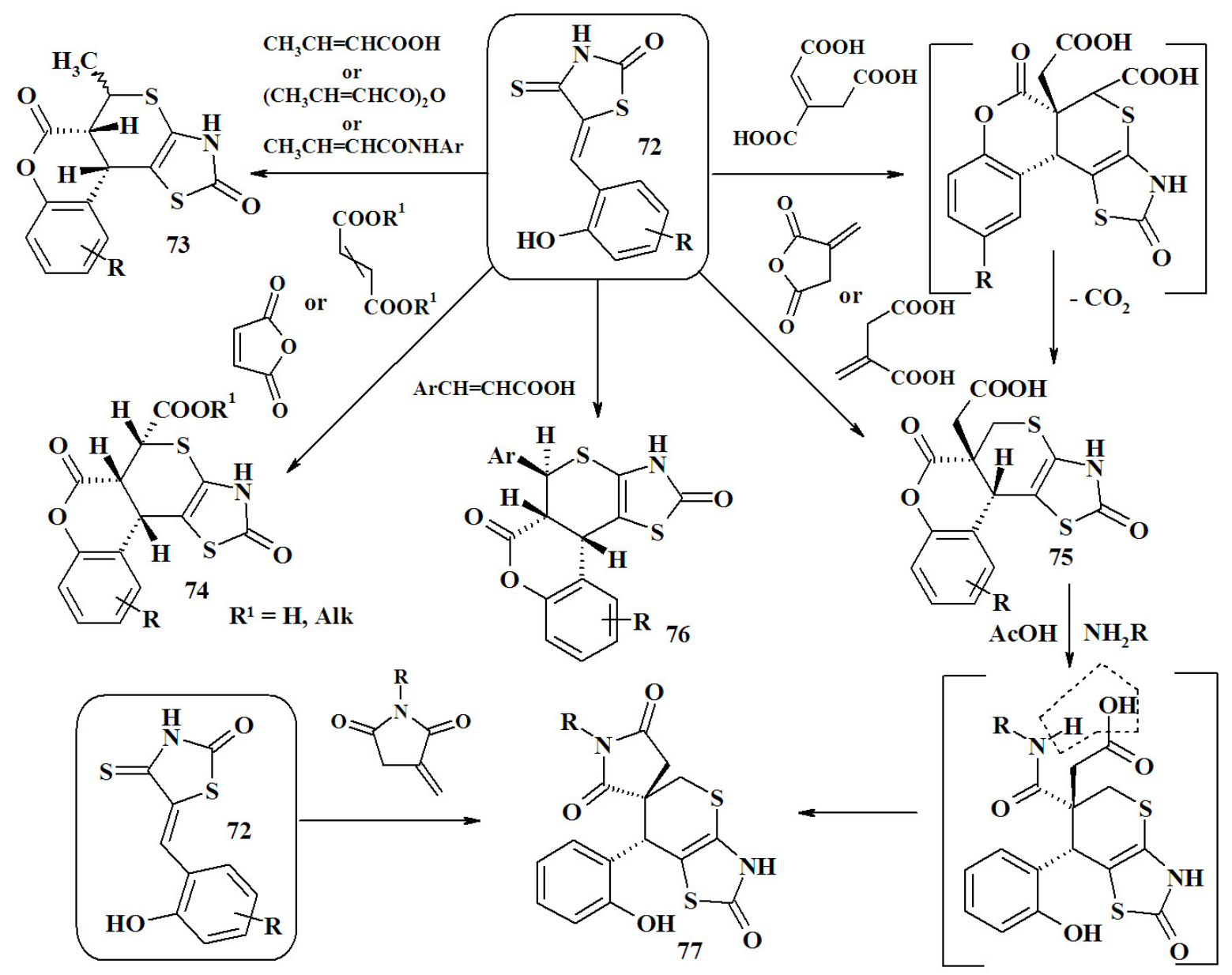

Figure 20. Scheme 19

cycle with bromine in acetic acid removes these obstacles to obtain the derivative 79 (Scheme 20, Figure 21) [38].

The reaction of 5-(2-hydroxyphenylmethylidene)isorhodanines with $2(5 \mathrm{H})$ furanone proceeded as a diastereoselective tandem acylation-hetero-Diels-Alder reaction providing novel rel-(5R,5aR,11bS) derivatives 80 (Scheme 21, Figure 22) [43].
The reactions between 5-(2-hydroxybenzylidene)-4-thioxo-2-thiazolidinones and arylidene pyruvic acids (Scheme 22, Figure 23) yielded the mixture of rel-(5S,5aR,11bR) 81 and rel$(5 \mathrm{R}, 5 \mathrm{aS}, 11 \mathrm{bR}) 81$ * diastereisomers in a 2:1 ratio [50]. At the same time, acroleine, crotonic and cynnamic aldehydes in this tandem hetero-DielsAlder-hemiacetal reaction (Scheme 23) diastereoselectively yielded rel-(5aR,6R,11bS)-6-hydroxy-<smiles>C#CC(=O)OC(C)(C(=O)O)[C@@H](CC)C(=O)O</smiles>

Figure 21. Scheme 20 


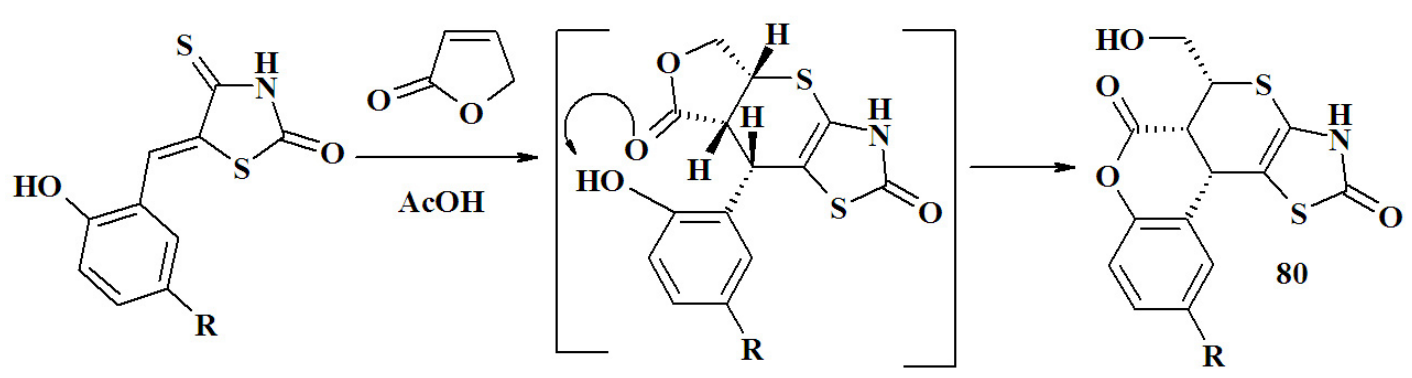

Figure 22. Scheme 21
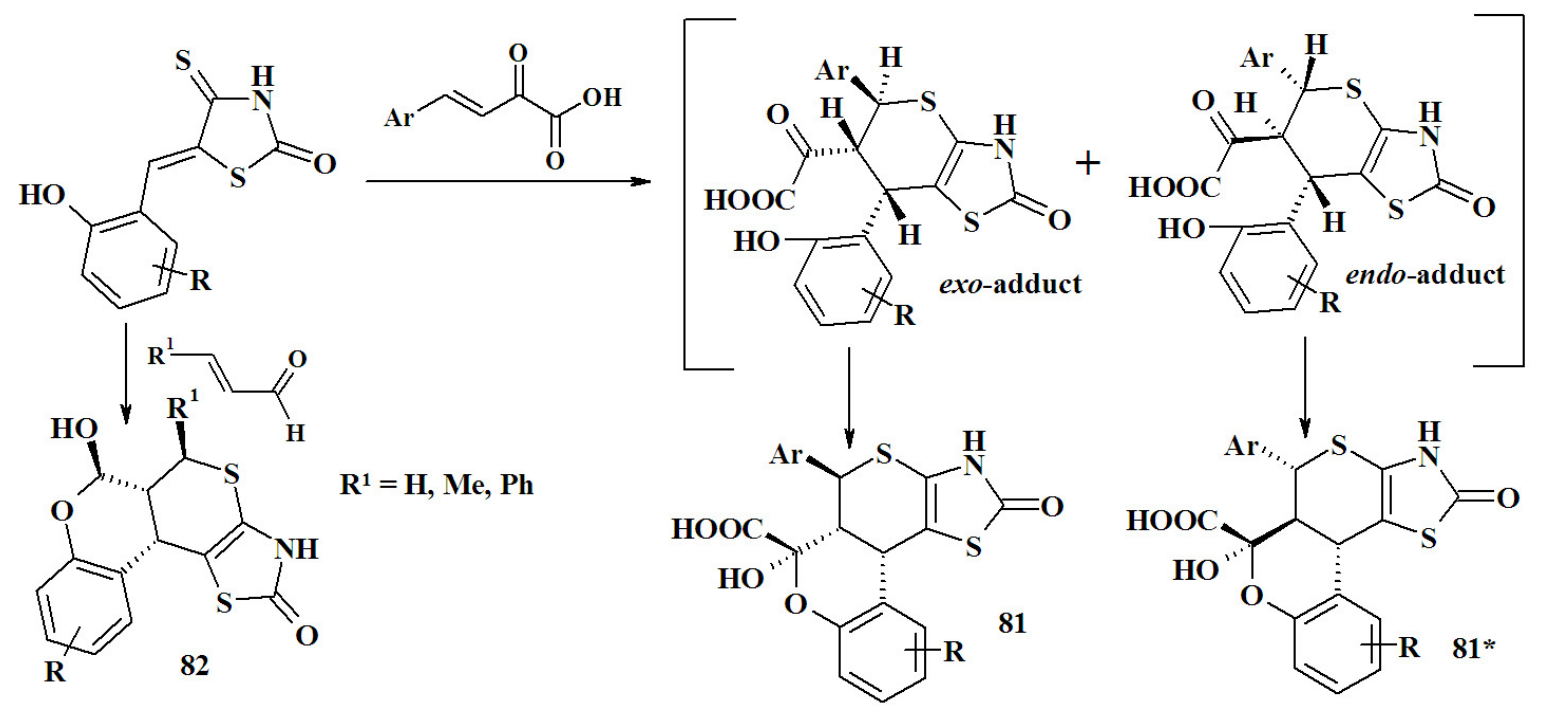

Figure 23. Scheme 22

$3,5 \mathrm{a}, 6,11 \mathrm{~b}$-tetrahydro-2H,5H-chromeno $\left[4^{\prime}, 3^{\prime}: 4,5\right]$ thiopyrano[2,3-d]thiazole-2-ones 82.

In addition to tandem reactions, domino reactions also play an important role in the synthesis of thiopyrano[2,3-d]thiazole-based compounds. A domino reaction involves two or more transformations, which result in the formation of bonds (usually $\mathrm{C}-\mathrm{C}$ bonds) and occur under the same reaction conditions without adding new reagents and/or catalysts. In this process, the subsequent reactions take place as a consequence of the functionality formed in the previous step, for example, obtaining isothiochromeno[4a,4-d] thiazole-2-ones 83 and chromeno $\left[4^{\prime}, 3^{\prime}: 4,5\right]$ thiopyrano[2,3-d]thiazole-2-(thi)ones 84,85 in the domino Knoevenagel-hetero-Diels-Alder reaction (Scheme 23, Figure 24) of isorhodanine with 3,7-dimethyl-6-octenal (( \pm citronelal) and 2-allyloxybenzaldehyde [51]. It should be noted that the reaction of isorhodanine with 2-allyloxybenzaldehyde yielded a mixture of trans- 84 and cis- 84 a isomers (5:1). Recrystallization from dioxane can provide individual trans-isomer 84 . Alternatively, tetracyclic derivatives 84,85 were synthesised via the domino thionation-hetero-Diels-Alder reaction of 5-(2-allyloxyphenylmethylidene)-4-thiazolidinones 86 .

Another example of the domino Knoevenagel-hetero-Diels-Alder reaction is the interaction of isorhodanine with 2-(2-methylallyloxy)- and 2-(cyclohexene-2-yloxy)benzaldehydes, 2-allyloxynaphthalaldehyde as well as 2-formylphenyl(E)-3- aryl-2-propenoates (Scheme 24, Figure 25). These reactions allowed the preparation of a series of pentacyclic derivatives characterised by trans(87-89) or cis-configuration (90) of $5 \mathrm{a}$ and $11 \mathrm{~b}$ protons. Interestingly, when 2-formylphenyl-(E)-3 -aryl-2-propenoates are used as reagents, stereoconfiguration of the final products 90 were similar to the derivatives 76 obtained in tandem acylationhetero-Diels-Alder reaction (Scheme 20, Figure 21). The stereochemistry of the final compounds 


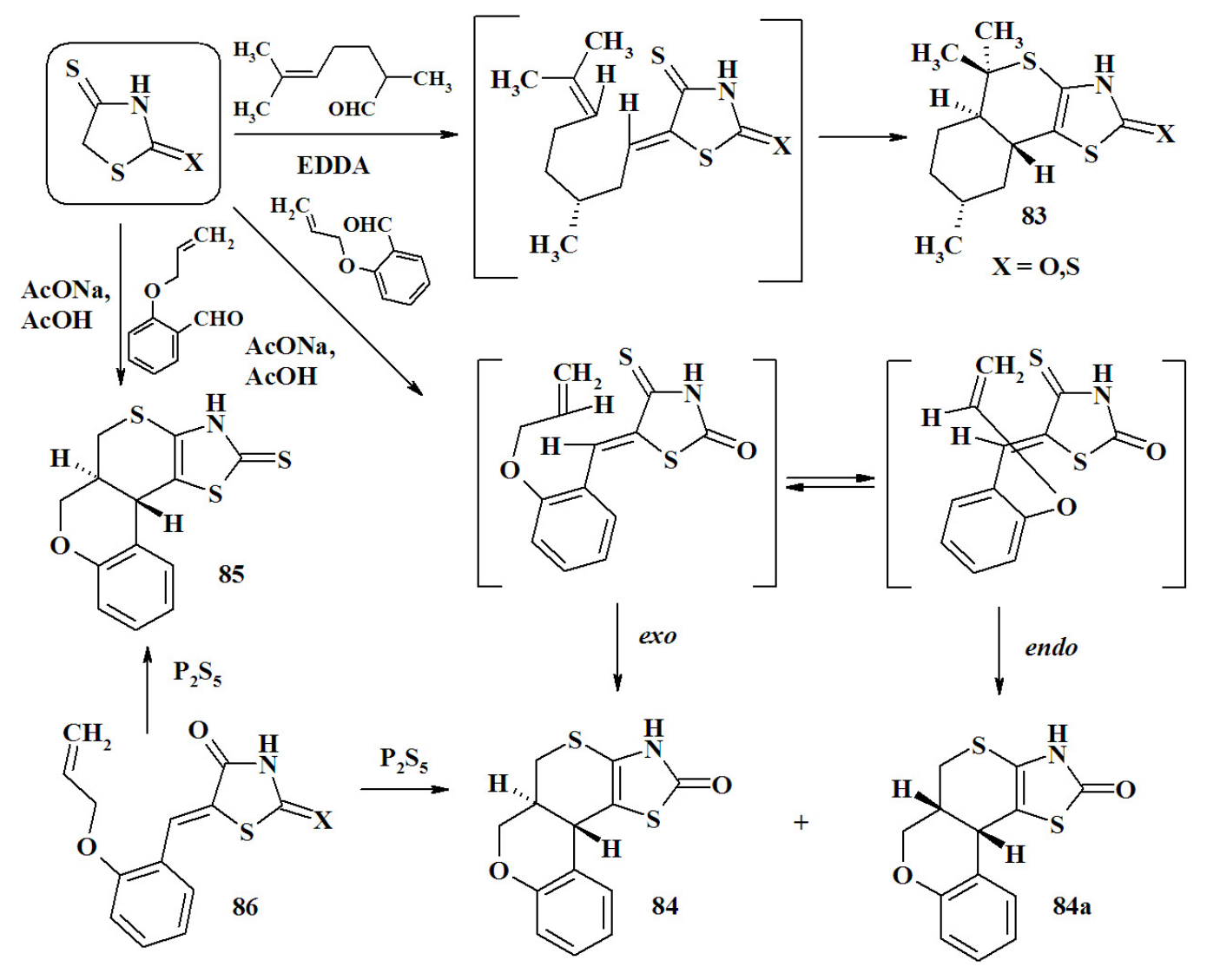

Figure 24. Scheme 23

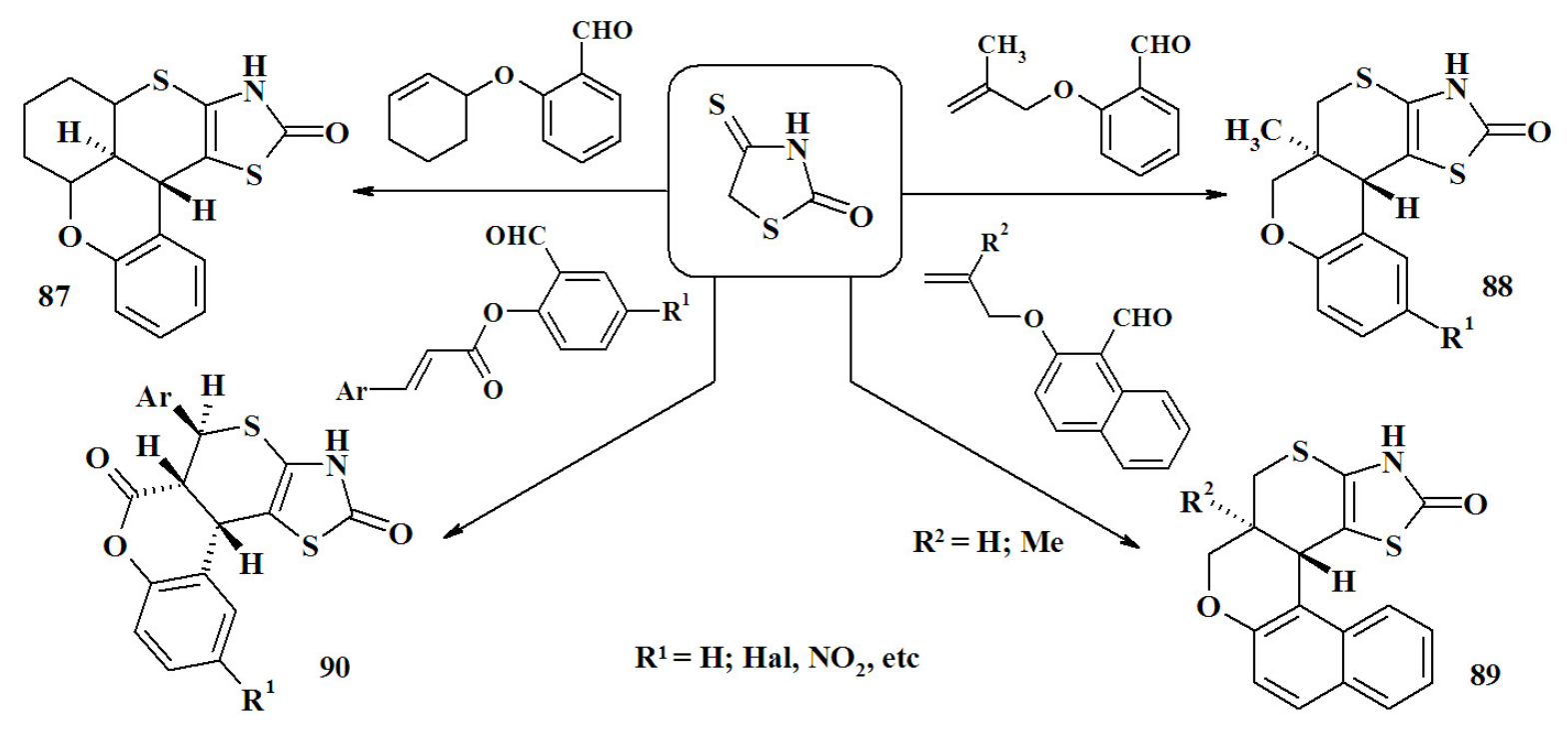

Figure 25. Scheme 24 
depends on the endo- and exo-orientation of the dienophile in the transition state. The presence of the allyl moiety in the molecule induces an exo transition state, in contrast to the cinnamoyl fragment which causes endo-orientation of the dienophile due to the orbital interactions [51].

\section{Conclusions and further perspectives}

The combination of several reactive centres in the main core led to different 4-thiazolidinonebased compound subtypes. The main routes for 5-ene-thiazolidinones synthesis and modification, mainly within a structure-based approach, can be compiled into the following groups:

, complication of the C5 fragment (following the thesis regarding the crucial impact of the C5 moiety for pharmacological activity);

, introduction of the substituents in the N3 position (especially fragments with carboxylic/amino/hydroxy groups);

, synthesis of isosteric heterocycles;

, combination with other pharmacologically attractive fragments within hybrid pharmacophore approach;

, annealing in complex heterocyclic systems;

, utilisation of 5-ene-thiazolidinones for the synthesis of other heterocycles.

The realisation of the presented routes is based on a combinatorial approach, privileged substructure-based diversity-oriented synthesis and molecular hybridisation. The chemical transformations cover mainly the reactions which involve the exocyclic double bond in $\mathrm{C5}$ position of the main core and correspond to the abovementioned direction of the 5-ene-4-thiazolidinones modification.

\section{Acknowledgements}

\section{Conflict of interest statement}

The authors declare no conflict of interest.

\section{Funding sources}

There are no sources of funding to declare.

\section{References}

1. Lesyk R, Zimenkovsky B. 4-Thiazolidones: Centenarian History, Current Status and Perspectives for Modern Organic and Medicinal Chemistry. Current Organ- ic Chemistry. 2004 Nov 1;8(16):1547-1577. https:// doi.org/10.2174/1385272043369773

2. Havrylyuk D, Zimenkovsky B, Lesyk R. Synthesis, Biological Activity of Thiazolidinones Bearing Indoline Moiety and Isatin Based Hybrids. Mini-Reviews in Organic Chemistry. 2014 Dec 24;12(1):66-87. https:// doi.org/10.2174/1570193x11666141028231910

3. Havrylyuk D, Roman O, Lesyk R. Synthetic approaches, structure activity relationship and biological applications for pharmacologically attractive pyrazole/pyrazoline-thiazolidine-based hybrids. European Journal of Medicinal Chemistry. 2016 May;113:145166. https://doi.org/10.1016/j.ejmech.2016.02.030

4. Tripathi AC, Gupta SJ, Fatima GN, Sonar PK, Verma A, Saraf SK. 4-Thiazolidinones: The advances continue.... European Journal of Medicinal Chemistry. 2014 Jan;72:52-77. https://doi.org/10.1016/j. ejmech.2013.11.017

5. Tomasic T, Masic L. Rhodanine as a Privileged Scaffold in Drug Discovery. Current Medicinal Chemistry. 2009 May 1;16(13):1596-1629. https://doi. org/10.2174/092986709788186200

6. Verma A, Saraf SK. 4-Thiazolidinone - A biologically active scaffold. European Journal of Medicinal Chemistry. 2008 May;43(5):897-905. https://doi. org/10.1016/j.ejmech.2007.07.017

7. Tomašić T, Peterlin Mašič L. Rhodanine as a scaffold in drug discovery: a critical review of its biological activities and mechanisms of target modulation. Expert Opinion on Drug Discovery. 2012 May 19;7(7):549-560. https://doi.org/10.1517/17460441.2 012.688743

8. Mendgen T, Steuer C, Klein CD. Privileged Scaffolds or Promiscuous Binders: A Comparative Study on Rhodanines and Related Heterocycles in Medicinal Chemistry. Journal of Medicinal Chemistry. 2012 Jan 11;55(2):743-753. https://doi.org/10.1021/jm201243p

9. Baell JB. Observations on screening-based research and some concerning trends in the literature. Future Medicinal Chemistry. 2010 Oct;2(10):1529-1546. https://doi.org/10.4155/fmc.10.237

10. Baell JB, Holloway GA. New Substructure Filters for Removal of Pan Assay Interference Compounds (PAINS) from Screening Libraries and for Their Exclusion in Bioassays. Journal of Medicinal Chemistry. 2010 Apr 8;53(7):2719-2740. https://doi.org/10.1021/ jm901137j

11. Baell J, Walters MA. Chemistry: Chemical con artists foil drug discovery. Nature. 2014 Sep;513(7519):481483. https://doi.org/10.1038/513481a

12. Kaminskyy D, Kryshchyshyn A, Lesyk R. 5-Ene-4-thiazolidinones - An efficient tool in medicinal chemistry. European Journal of Medicinal Chemistry. 2017 Nov;140:542-594. https://doi.org/10.1016/j. ejmech.2017.09.031

13. Kaminskyy D, Kryshchyshyn A, Lesyk R. Recent developments with rhodanine as a scaffold for drug discovery. Expert Opinion on Drug Discovery. 2017 Oct 11;12(12):1233-1252. https://doi.org/10.1080/174 60441.2017 .1388370

14. Lesyk RB, Zimenkovsky BS, Kaminskyy DV, Kryshchyshyn AP, Havryluk DY, Atamanyuk DV, Subtel'na 
IY, Khyluk DV. Thiazolidinone motif in anticancer drug discovery. Experience of DH LNMU medicinal chemistry scientific group. Biopolymers and Cell. 2011 Mar 20;27(2):107-117. https://doi.org/10.7124/ bc.000089

15. Kryshchyshyn A, Roman O, Lozynskyi A, Lesyk R. Thiopyrano[2,3-d]Thiazoles as New Efficient Scaffolds in Medicinal Chemistry. Scientia Pharmaceutica. 2018 Jun 14;86(2):26. https://doi.org/10.3390/ scipharm86020026

16. Mosula L, Zimenkovsky B, Havrylyuk D, Missir A, Chiriță I, Lesyk R. Synthesis and antitumor activity of novel 2-thioxo-4-thiazolidinones with benzothiazole moieties. Farmacia. 2009;57(3):321-30.

17. Havrylyuk D, Mosula L, Zimenkovsky B, Vasylenko 0 , Gzella A, Lesyk R. Synthesis and anticancer activity evaluation of 4-thiazolidinones containing benzothiazole moiety. European Journal of Medicinal Chemistry. 2010 Nov;45(11):5012-5021. https://doi. org/10.1016/j.ejmech.2010.08.008

18. Kaminskyy D, den Hartog GJ, Wojtyra M, Lelyukh M, Gzella A, Bast A, Lesyk R. Antifibrotic and anticancer action of 5-ene amino/iminothiazolidinones. European Journal of Medicinal Chemistry. 2016 Apr;112:180195. https://doi.org/10.1016/j.ejmech.2016.02.011

19. Senkiv J, Finiuk N, Kaminskyy D, Havrylyuk D, Wojtyra M, Kril I, Gzella A, Stoika R, Lesyk R. 5-Ene-4-thiazolidinones induce apoptosis in mammalian leukemia cells. European Journal of Medicinal Chemistry. 2016 Jul;117:33-46. https://doi.org/10.1016/j. ejmech.2016.03.089

20. Wojtyra MN, Lesyk RB. Синтез 3-піридилзаміщених 4-тіазолідинонів як потенційних біологічно активних сполук. Фармацевтичний часопис. 2017 Mar 24;(1). https://doi.org/10.11603/23120967.2017.1.7533

21. Wojtyra M, Lesyk R, Zimenkovsky B, Grellier P. (Z)-(5[5-(3,5-diaryl-4,5-dihydropyrazol-1-yl-methylidene)3-(pyridine-3-yl)-2-thioxothiazolidin-4-ones exhibiting antitrypanosomal action. 2017 Oct 10; UA 119822 (Ukraine).

22. Holota S, Kryshchyshyn A, Derkach H, Trufin $Y$ Demchuk I, Gzella A, Grellier P, Lesyk R. Synthesis of 5-enamine-4-thiazolidinone derivatives with trypanocidal and anticancer activity. Bioorganic Chemistry. 2019 May;86:126-136. https://doi. org/10.1016/j.bioorg.2019.01.045

23. Lelyukh M, Havrylyuk D, Lesyk R. Synthesis and Anticancer Activity of Isatin, Oxadiazole and 4-Thiazolidinone Based Conjugates. Chemistry \& Chemical Technology. 2015 Mar 15;9(1):29-36. https://doi. org/10.23939/chcht09.01.029

24. Kaminskyy D. A Facile Synthesis and Anticancer Activity Evaluation of Spiro[Thiazolidinone-Isatin] Conjugates. Scientia Pharmaceutica. 2011;79(4):763777. https://doi.org/10.3797/scipharm.1109-14

25. Havrylyuk D, Zimenkovsky B, Vasylenko O, Zaprutko L, Gzella A, Lesyk R. Synthesis of novel thiazolone-based compounds containing pyrazoline moiety and evaluation of their anticancer activity. European Journal of Medicinal Chemistry. 2009 Apr;44(4):13961404. https://doi.org/10.1016/j.ejmech.2008.09.032
26. Ouyang G, Cai X, Chen Z, Song B, Bhadury PS, Yang S, Jin L, Xue W, Hu D, Zeng S. Synthesis and Antiviral Activities of Pyrazole Derivatives Containing an Oxime Moiety. Journal of Agricultural and Food Chemistry. 2008 Nov 12;56(21):10160-10167. https://doi. org/10.1021/jf802489e

27. Havrylyuk D, Zimenkovsky B, Vasylenko O, Gzella A, Lesyk R. Synthesis of New 4-Thiazolidinone-, Pyrazoline-, and Isatin-Based Conjugates with Promising Antitumor Activity. Journal of Medicinal Chemistry. 2012 Oct 9;55(20):8630-8641. https://doi. org/10.1021/jm300789g

28. Kryshchyshyn A, Kaminskyy D, Karpenko O, Gzella A, Grellier P, Lesyk R. Thiazolidinone/thiazole based hybrids - New class of antitrypanosomal agents. European Journal of Medicinal Chemistry. 2019 Jul;174:292-308. https://doi.org/10.1016/j. ejmech.2019.04.052

29. Kaminskyy D, Bednarczyk-Cwynar B, Vasylenko O, Kazakova O, Zimenkovsky B, Zaprutko L, Lesyk R. Synthesis of new potential anticancer agents based on 4-thiazolidinone and oleanane scaffolds. Medicinal Chemistry Research. 2011 Nov 25;21(11):35683580. https://doi.org/10.1007/s00044-011-9893-9

30. Komarista I. Synthesis, transformations and biological activity of some azolidones and their condensed derivatives. Moscow, USSR: I.M. Sechenov First State Medical Institute; 1989.

31. Komaritsa ID, Baranov SN, Grishuk AP. 4-Thiazolidines, derivatives and analogs. Chemistry of Heterocyclic Compounds. 1967 Jul;3(2):533-534. https:// doi.org/10.1007/bf00481594

32. Plevachuk NE, Komaritsa ID. A study of azolidones and their derivatives. Chemistry of Heterocyclic Compounds. 1970 Feb;6(2):144-145. https://doi. org/10.1007/bf00474983

33. Grischuk AP, Komaritsa ID, Baranov SN. 4-Thionazolidones, derivatives and analogs. Chemistry of Heterocyclic Compounds. 1968;2(5):541-543. https://doi. org/10.1007/bf00477515

34. Lozynskyi A, Zimenkovsky B, Lesyk R. Synthesis and Anticancer Activity of New Thiopyrano[2,3-d] thiazoles Based on Cinnamic Acid Amides. Scientia Pharmaceutica. 2014;82(4):723-733. https://doi. org/10.3797/scipharm.1408-05

35. Lozynskyi A, Zasidko V, Atamanyuk D, Kaminskyy D, Derkach H, Karpenko O, Ogurtsov V, Kutsyk R, Lesyk $R$. Synthesis, antioxidant and antimicrobial activities of novel thiopyrano[2,3-d]thiazoles based on aroylacrylic acids. Molecular Diversity. 2017 Apr 19;21(2):427-436. https://doi.org/10.1007/s11030017-9737-8

36. Lozynskyi A, Zimenkovsky B, Nektegayev I, Lesyk R. Arylidene pyruvic acids motif in the synthesis of new thiopyrano[2,3-d]thiazoles as potential biologically active compounds. Heterocyclic Communications. 2015 Jan 1;21(1). https://doi.org/10.1515/hc-20140204

37. Zelisko N, Atamanyuk D, Ostapiuk Y, Bryhas A, Matiychuk V, Gzella A, Lesyk R. Synthesis of fused thiopyrano[2,3-d][1,3]thiazoles via hetero-Diels-Alder reaction related tandem and domino process- 
es. Tetrahedron. 2015 Dec;71(50):9501-9508. https:// doi.org/10.1016/j.tet.2015.10.019

38. Zelisko N, Atamanyuk D, Vasylenko O, Bryhas A, Matiychuk V, Gzella A, Lesyk R. Crotonic, cynnamic, and propiolic acids motifs in the synthesis of thiopyrano[2,3-d][1,3]thiazoles via heteroDiels-Alder reaction and related tandem processes. Tetrahedron. 2014 Jan;70(3):720-729. https://doi. org/10.1016/j.tet.2013.11.083

39. Lozynskyi A, Golota S, Zimenkovsky B, Atamanyuk D, Gzella A, Lesyk R. Synthesis, anticancer and antiviral activities of novel thiopyrano[2,3-d]thiazole-6carbaldehydes. Phosphorus, Sulfur, and Silicon and the Related Elements. 2016 Mar 30;191(9):1245-1249. https://doi.org/10.1080/10426507.2016.1166108

40. Kryshchyshyn AP, Atamanyuk DV, Kaminskyy DV, Grellier P, Lesyk RB. Investigation of anticancer and anti-parasitic activity of thiopyrano[2,3-d]thiazoles bearing norbornane moiety. Biopolymers and Cell. 2017 Jun 30;33(3):183-205. https://doi.org/10.7124/ bc.00094f

41. Lesyk R, Zimenkovsky B, Atamanyuk D, Jensen F, Kieć-Kononowicz K, Gzella A. Anticancer thiopyrano[2,3-d][1,3]thiazol-2-ones with norbornane moiety. Synthesis, cytotoxicity, physico-chemical properties, and computational studies. Bioorganic \& Medicinal Chemistry. 2006 Aug;14(15):52305240. https://doi.org/10.1016/j.bmc.2006.03.053

42. Atamanyuk D, Zimenkovsky B, Lesyk R. Synthesis and anticancer activity of novel thiopyrano[2,3-d]thiazole-based compounds containing norbornane moiety. Journal of Sulfur Chemistry. 2008 Apr;29(2):151162. https://doi.org/10.1080/17415990801911723

43. Lozynskyi A, Zimenkovsky B, Karkhut A, Polovkovych S, Gzella AK, Lesyk R. Application of the $2(5 \mathrm{H}$ )furanone motif in the synthesis of new thiopyrano[2,3- $d$ ]thiazoles via the hetero-Diels-Alder reaction and related tandem processes. Tetrahedron Letters. 2016 Jul;57(30):3318-3321. https://doi. org/10.1016/j.tetlet.2016.06.060

44. Zelisko N, Karpenko O, Muzychenko V, Gzella A, Grellier P, Lesyk R. trans -Aconitic acid-based hetero -Diels-Alder reaction in the synthesis of thiopyrano[2,3- d ][1,3]thiazole derivatives. Tetrahedron Letters. 2017 May;58(18):1751-1754. https://doi. org/10.1016/j.tetlet.2017.03.062

45. Atamanyuk D. Synthesis and Biological Activity of New Thiopyrano[2,3-d]thiazoles Containing a Naphthoquinone Moiety. Scientia Pharmaceutica. 2013;81(2):423-436. https://doi.org/10.3797/ scipharm.1301-13

46. Atamanyuk D, Zimenkovsky B, Atamanyuk V, Lesyk R. 5-Ethoxymethylidene-4-thioxo-2-thiazolidinone as Versatile Building Block for Novel Biorelevant Small Molecules with Thiopyrano[2,3-d][1,3]thiazole Core. Synthetic Communications. 2013 Oct 29;44(2):237244. https://doi.org/10.1080/00397911.2013.800552

47. Lesyk R, Kaminskyy D, Vasylenko O, Atamanyuk D, Gzella A. Isorhodanine and Thiorhodanine Motifs in the Synthesis of Fused Thiopyrano[2,3-d][1,3]thiazoles. Synlett. 2011 May 26;2011(10):1385-1388. https://doi.org/10.1055/s-0030-1260765

48. Zelisko NI, Finiuk NS, Shvets VM, Medvid YO, Stoika RS, Lesyk RB. Screening of spiro-substituted thiopyrano[2,3-d]thiazoles for their cytotoxic action on tumor cells. Biopolymers and Cell. 2017 Aug 31;33(4):282-290. https://doi.org/10.7124/bc.00095a

49. Zelisko N, Atamanyuk D, Vasylenko O, Grellier P, Lesyk R. Synthesis and antitrypanosomal activity of new 6,6,7-trisubstituted thiopyrano[2,3-d][1,3]thiazoles. Bioorganic \& Medicinal Chemistry Letters. 2012 Dec;22(23):7071-7074. https://doi.org/10.1016/j. bmcl.2012.09.091

50. Lozynskyi A, Zimenkovsky B, Gzella AK, Lesyk R. Arylidene Pyruvic Acids Motif in the Synthesis of New 2H,5H-Chromeno[4',3':4,5] thiopyrano[2,3-d]thiazoles via Tandem Hetero-Diels-Alder-Hemiacetal Reaction. Synthetic Communications. 2015 Aug 3;45(19):2266-2270. https://doi.org/10.1080/003979 11.2015 .1076004

51. Matiychuk VS, Lesyk RB, Obushak MD, Gzella A, Atamanyuk DV, Ostapiuk YV, Kryshchyshyn AP. A new domino-Knoevenagel-hetero-Diels-Alder reaction. Tetrahedron Letters. 2008 Jul;49(31):4648-4651. https://doi.org/10.1016/j.tetlet.2008.05.062 